\title{
Developing new scenarios for water allocation negotiations: a case study of the Euphrates River Basin
}

\author{
Mohammad Reza Jarkeh $^{1}$, Ameneh Mianabadi ${ }^{2}$, and Hojjat Mianabadi ${ }^{3}$ \\ ${ }^{1}$ Department of Water engineering, University of Zabol, Zabol, 9861335586, Iran \\ ${ }^{2}$ Department of Water engineering, Ferdowsi University of Mashhad, Mashhad, 9177948974, Iran \\ ${ }^{3}$ Department of Water Resources, Faculty of Civil Engineering and Geosciences, Delft University of \\ Technology, Stevinweg 1, 2628 CN, Delft, the Netherlands \\ Correspondence to: M. R. Jarkeh (mohammad.reza.jargeh@uoz.ac.ir, m.jargeh@gmail.com)
}

Published: 17 October 2016

\begin{abstract}
Mismanagement and uneven distribution of water may lead to or increase conflict among countries. Allocation of water among trans-boundary river neighbours is a key issue in utilization of shared water resources. The bankruptcy theory is a cooperative Game Theory method which is used when the amount of demand of riparian states is larger than total available water. In this study, we survey the application of seven methods of Classical Bankruptcy Rules (CBRs) including Proportional (CBR-PRO), Adjusted Proportional (CBR-AP), Constrained Equal Awards (CBR-CEA), Constrained Equal Losses (CBR-CEL), Piniles (CBR-Piniles), Minimal Overlap (CBR-MO), Talmud (CBR-Talmud) and four Sequential Sharing Rules (SSRs) including Proportional (SSR-PRO), Constrained Equal Awards (SSR-CEA), Constrained Equal Losses (SSR-CEL) and Talmud (SSRTalmud) methods in allocation of the Euphrates River among three riparian countries: Turkey, Syria and Iraq. However, there is not a certain documented method to find more equitable allocation rule. Therefore, in this paper, a new method is established for choosing the most appropriate allocating rule which seems to be more equitable than other allocation rules to satisfy the stakeholders. The results reveal that, based on the new propose model, the CBR-AP seems to be more equitable to allocate the Euphrates River water among Turkey, Syria and Iraq.
\end{abstract}

\section{Introduction}

About $40 \%$ of world population lives in transboundary river basins which are shared among two or more countries (Prins, 2013). Based on the Transboundary Freshwater Dispute Database (TFDD), 276 transboundary freshwater river basins are shared among almost 148 countries (De Stefano et al., 2012). These basins cover nearly half of the Earth's land surface (United Nations, 2014). In the Middle East, water - as a scarce resource - has become increasingly vital for economic and agricultural development (Gleick, 1993). Mismanagemen uneven distribution of water and the increase in demands as well as distrust among riparian countries, may lead to conflict in shared river basins (Homer-Dixon, 1994). The important role of water in supporting the demands of growing population, crop production, soil degradation and other environmental effects, can cause the freshwater to be a source of conflict in the twentieth century (Westing, 1986). However, it is argued that the outbreak of war is unexpected by two reasons. First, there are almost 450 agreements on international waters signed from 1820 to 2007 (United Nations, 2014) which confirm the tendency of nations to dispute resolution instead of war. Second, starting a war needs many factors such as political, economic, cultural, religious and historical factors (Gleick, 1993). Thus, shared water resource is a source of both conflict and cooperation. Although an international agreement among riparian countries can easily overcome the territorial water resource problem, the basic challenge happens when water demands of riparian countries are more than available water.

Equitable allocation of shared water among riparian states is a complex process and one of the most important is- 
sues in quantitative conflict resolution, specifically at international scale. Therefore, water scarcity should be analysed with respect to five prospective in the literature of hydropolitics: economic, legal, technical, environmental and security issues (Dolatyar and Gray, 2000). Negotiation is necessary for riparian countries to reach an agreement peacefully over shared water resources. However, the complex problem in consensus building to reach an equitable and reasonable agreement (Rieu-Clarke et al., 2012) is how to allocate water among riparian countries.

Bankruptcy theory is a branch of cooperative Game Theory which can be used in dispute resolution and resources allocation when demand or claim of countries is more than the total available resources (Ansink and Weikard, 2012). The bankruptcy theory was introduced in the seminal papers by O'Neill (1982) and Aumann and Maschler (1985) and some aspects of this theory have been studied by several researchers (Alcalde et al., 2014; Aumann and Maschler, 1985; Hendrickx et al., 2005; Lorenzo-Freire et al., 2010; O'Neill, 1982; Pérez et al., 2010; Thomson, 2003, 2012). Few researchers tried to apply the bankruptcy rules to allocate the shared available water among riparian countries (Mianabadi et al., 2014, 2015; Madani and Zarezadeh, 2012). However, due to different definition of fairness, there is no certain documented method to choose the most appropriate allocation rule. Therefore, in this paper we established a new method to choose the most appropriate allocating rule which seems to be more equitable and reasonable than other allocation rules to satisfy the riparian countries. To evaluate this new proposed method, we applied seven Classical Bankruptcy Rules (CBRs) including Proportional (CBRPro), Constrained Equal Awards (CBR-CEA), Constrained Equal Losses (CBR-CEL), CBR-Talmud, Adjusted Proportional (CBR-AP), CBR-Piniles and Minimal Overlap (CBRMO) and four Sequential Sharing Rules (SSRs) including SSR-Pro, SSR-CEA, SSR-CEL and SSR-Talmud in allocating the Euphrates River water among three riparian countries.

\section{Euphrates River basin}

The Euphrates River is the longest river in the west of Asia (Meyers, 1997) with three riparian countries: Iraq, Syria and Turkey (ESCWA, 2013). It originates from the mountains in the east of Turkey and after following into Syria and Iraq, it connects to the Arvand Rud which goes into the Persian Gulf. The length of river, from the source of Murat Su to the confluence with the Tigris River is $3000 \mathrm{~km} ; 1230 \mathrm{~km}$ in Turkey, $710 \mathrm{~km}$ in Syria and $1060 \mathrm{~km}$ in Iraq (Frenken, 2009) (Fig. 1). After constructing the Keban dam in 1974 and Karakaya dam in 1987, related to the Southeastern Anatolia Project, or Guneydogu Anadolu Projesi, GAP, project, water conflicts raised between Turkey and Syria (Kaya, 1998). Although the GAP project had been scheduled to be completed in 2010, it has been delayed because the World Bank

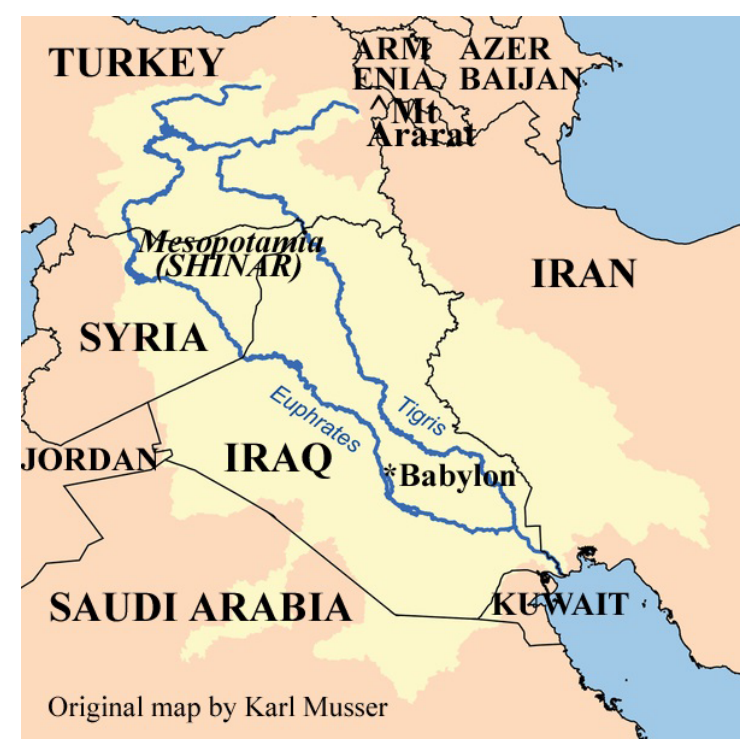

Figure 1. The Euphrates-Tigris Rivers basin (created by Karl Musser).

has withheld funding the project due to the lack of an official agreement on water sharing between Turkey and the downstream states on the Euphrates and Tigris Rivers (Jongerden, 2010). The contribution of the riparian countries for draining to the Euphrates River and their claim on this river are illustrated in Table 1 (Ibrahim et al., 2004; Beaumont, 1998).

\section{Bankruptcy allocation rules}

\subsection{Classical Bankruptcy problem}

Bankruptcy theory aims to allocate available resource (asset) among stakeholders (creditors) to reach an equitable share of resources, when the asset is not sufficient to satisfy all stakeholders. To determine the meaning of "equitable", a large variety of factors, including population, geography, availability of alternative resources, social and economic needs, etc., should be considered during negotiations over the allocation of resources (Gleick, 1993).

\subsubsection{Definition}

A bankruptcy problem with set of $n$ claimants, $N=$ $\{1, \ldots, i, \ldots, n\}$ is an ordered pair of $(E, \underline{c}) \in R \times R^{n}$, where $0 \leq c_{1} \leq c_{2} \leq \ldots \leq c_{n}$ and $0 \leq E \leq D$ such that $D$ is the total demand:

$D=\sum_{i=1}^{n} c_{i}$.

$E$ is the total assets which have to be divided among $n$ claimants with claims of $c_{i}$ on $E$. An allocation rule is a function that assigns a solution of $f(E, \underline{c})=$ $\left(f_{1}(E, \underline{\boldsymbol{c}}), f_{2}(E, \underline{\boldsymbol{c}}), \ldots, f_{n}(E, \underline{\boldsymbol{c}})\right)$ to a bankruptcy problem 
Table 1. The rate of contribution and claim of riparian countries on the Euphrates River (Beaumont, 1998; Ibrahim et al., 2004).

\begin{tabular}{lrrrr}
\hline $\begin{array}{l}\text { Riparian } \\
\text { Countries }\end{array}$ & $\begin{array}{r}\text { Claim } \\
(\mathrm{MCM} / \text { year })\end{array}$ & $\begin{array}{r}\text { Claim } \\
(\%)\end{array}$ & $\begin{array}{r}\text { Contribution } \\
(\mathrm{MCM} / \text { year })\end{array}$ & $\begin{array}{r}\text { Contribution } \\
(\%)\end{array}$ \\
\hline Turkey & 14000 & 25.6 & 31580 & 88.8 \\
Syria & 12600 & 23 & 4000 & 11.2 \\
Iraq & 28100 & 51.4 & 0 & 0 \\
\hline Total & 54700 & 100 & 35580 & 100 \\
\hline
\end{tabular}

$(E, \underline{c})$ such that (Curiel et al., 1987):

$f_{1}(E, \underline{c}) \geq 0$ for every $i \in N$ (Individual rationality)

$\sum_{i=1}^{n} f_{1}(E, \underline{c})=E$ (Efficiency).

In this paper allocation vector of $f(E, \underline{c})$ will be shown by $\underline{\boldsymbol{x}}=\left\langle x_{1}, x_{2}, \ldots, x_{n}\right\rangle$.

\subsubsection{Proportional rule (PRO)}

Proportional method can be described as follow:

$x_{i}^{\text {pro }}=\mu c_{i}$ where $\mu=E / D$.

The $\mu$ in this rule is the proportional coefficient.

\subsubsection{Constrain Equal Award (CEA)}

Using this method, for all $c_{i}$ there exists $\mu>0$, such that:

$x_{i}^{\mathrm{CEA}}=\min \left\{\mu, c_{i}\right\}$.

The $\mu$ is calculated by $\sum_{i \in N} \min \left\{\mu, c_{i}\right\}=E$.

\subsubsection{Constrained Equal Losses (CEL)}

Using this method, for all $c_{i}$ there exists $\mu>0$, such that

$x_{i}^{\mathrm{CEL}}=\max \left\{0, c_{i}-\mu\right\}$

where $\sum_{i \in N} \max \left\{0, c_{i}-\mu\right\}=E$.

\subsubsection{Talmud}

This rule is the combination of CEA and CEL rules and is described as follow:

$$
x_{i}^{\mathrm{TAL}}= \begin{cases}\operatorname{CEA}\left\{\frac{1}{2} c_{i}, E\right\} & \text { if } E \leq \frac{1}{2} C \\ \frac{1}{2} c_{i}+\mathrm{CEL}\left\{\frac{1}{2} c_{i}, E-\frac{1}{2} C\right\} & \text { otherwise. }\end{cases}
$$

\subsubsection{Piniles}

For each $c_{i}, x_{i}^{\mathrm{Pin}}$ is calculated as follow: (Bosmans and Lauwers, 2007)

$$
x_{i}^{\mathrm{Pin}}= \begin{cases}x_{i}^{\mathrm{CEA}}\left(\frac{1}{2} \underline{\boldsymbol{c}}, E\right) & \text { if } E \leq \frac{D}{2} \\ \frac{1}{2} \underline{\boldsymbol{c}}+x_{i}^{\mathrm{CEA}}\left(\frac{1}{2} \underline{\boldsymbol{c}}, E-\frac{D}{2}\right) & \text { if } E \geq \frac{D}{2} .\end{cases}
$$

\subsubsection{Minimal Overlap (MO) rules}

Ibn Ezra's rule

Consider the class of $\psi=\left\{(E, \underline{c}): c_{n} \geq E\right\}$. The Ibn Ezra's rule is a function of $f^{\mathrm{IE}}(E, \underline{\boldsymbol{c}}): \psi \rightarrow R_{+}^{n}$ which is calculated by

$f_{i}^{\mathrm{IE}}(E, \underline{c})=x_{i}^{\mathrm{IE}}=\sum_{j=1}^{i} \frac{\min \left\{E, c_{j}\right\}-\min \left\{E, c_{j-1}\right\}}{n-j+1}$

where $c_{0}=0$.

However, this rule is applicable only for a restricted class of bankruptcy problem.

A formal description for Minimal Overlap rule which is a modification of Ibn Ezra's rule for all classes of bankruptcy problem, was proposed by Chun and Thomson (2005). Awards vectors are chosen by minimizing the extent of conflict over each available unit (Chun and Thomson, 2005). For each $c_{i}$, claims on specific parts of $E$ are arranged in such a way that starting from the highest claim, and in decreasing order. So there is a minimal overlap between them; then, for each unit, equal division among all agents will be applied (Alcalde et al., 2008). Two conditions should be considered (Alcalde et al., 2014).

If $E \geq c_{n}$

$x_{i}^{\mathrm{MO}}=\sum_{j=1}^{i} \frac{\min \left\{c_{j}, t\right\}-\min \left\{c_{j-1}, t\right\}}{n-j+1}+\max \left\{c_{i}-t, 0\right\}$

where $c_{0}=0$ and $t$ is the unique solution for

$\sum_{k=1}^{n} \max \left\{c_{k}-t, 0\right\}=E-t$.

If $E<c_{n}$

$x_{i}^{\mathrm{MO}}=x_{i}^{\mathrm{IE}}=\sum_{j=1}^{i} \frac{\min \left\{E, c_{j}\right\}-\min \left\{E, c_{j-1}\right\}}{n-j+1}$.

\section{Adjusted Proportional (AP)}

The adjusted proportional (AP) rule, which is a generalization of 2-player contested garment principle (appears in Babylonian Talmud, Baba Metzia, 2a) (Dagan and Volij, 1993), recommends to allocate the asset among claimants as follow (Curiel et al., 1987): 


$$
x_{i}^{\mathrm{AP}}= \begin{cases}v_{i}+\left[\frac{c_{i}-v_{i}}{\sum_{j \in N}\left(c_{j}-v_{j}\right)} \times\left(E-\sum_{j \in N} v_{j}\right)\right] & \text { if } 0<E<D \\ c_{i} & \text { if } E=D \\ 0 & \text { if } E=0\end{cases}
$$

where

$v_{i}=\max \left\{0, E-\sum_{j \neq i} c_{j}\right\}$.

This method assigns more allocation to stakeholders with more claims.

\subsection{Sequential Sharing Rules (SSRs)}

In SSR, Ansik and Weikard (2012) considered an ordered set $N$ of $n \geq 2$ stakeholders in which country 1 is the most upstream and country $n$ is the most downstream. Stakeholder $i$ is upstream of $j$ if $i<j$. The set of stakeholders downstream of $i$ is denoted by $D_{i}=\{j \in N ; j>i\}$ and the set of stakeholders upstream of $i$ is denoted by $U_{i}=\{j \in N ; j<i\}$. Contribution of country $i$ to increase flow in the river is shown by $e_{i} \geq 0 ; \underline{\boldsymbol{e}}=\left\langle e_{1}, \ldots, e_{n}\right\rangle$. The claimant vector is described by $\underline{\boldsymbol{c}}=\left\langle c_{1}, \ldots, c_{n}\right\rangle$.

A SSR problem is a triple vector of $\omega=\langle N, \underline{\boldsymbol{e}}, \underline{\boldsymbol{c}}\rangle$. The total available water on the territory of agent $i$ is

$E_{i}=e_{i}+\sum_{j \in U_{i}}\left(e_{j}-x_{j}\right)$

while $\sum_{j \in U_{i}}\left(e_{j}-x_{j}\right)$ refers to the unallocated water to all upstream countries of country $i$.

Downstream excess claims are defined as follow:

$c_{D_{i}}=\sum_{j \in D_{i}}\left(c_{j}-e_{j}\right)$.

In order to solve SSR, a bankruptcy rule is applied to the sequence of $\left(\omega_{1}, \ldots, \omega_{i}, \ldots, \omega_{n}\right)$, where $\omega_{i}=$ $\left\langle\left\{i, D_{i}\right\},\left(E_{i}, 0\right),\left(c_{i}, c_{D_{i}}\right)\right\rangle$.

There are two major differences between CBRs and SSRs. First, in CBRs all agents have equal position, but in SSRs, the agents are ordered linearly, in the direction of river flow. Second, in CBRs resource is completely separated from the agents while in SSRs the resource is initially endowed to the agents (Ansink and Weikard, 2012).

\subsubsection{SSR based on PRO}

For all $\omega_{i}=\left\langle\left\{i, D_{i}\right\},\left(E_{i}, 0\right),\left(c_{i}, c_{D_{i}}\right)\right\rangle$ there exists $\lambda>0$, so that $x_{i}^{\mathrm{Pro}}=\lambda c_{i}$ and $x_{D_{i}}^{\mathrm{Pro}}=\lambda c_{D_{i}}$. Then $\lambda$ is

$\lambda=\frac{E_{i}}{c_{i}+c_{D_{i}}}$.

\subsubsection{SSR based on CEA}

For all $\omega_{i}=\left\langle\left\{i, D_{i}\right\},\left(E_{i}, 0\right),\left(c_{i}, c_{D_{i}}\right)\right\rangle$ there exists $\lambda>0$, so that

$\left\{\begin{array}{l}x_{i}^{\mathrm{CEA}}=\min \left\{c_{i}, \lambda\right\} \\ x_{D_{i}}^{\mathrm{CEA}}=\min \left\{c_{D_{i}}, \lambda\right\} .\end{array}\right.$

\subsubsection{SSR based on CEL}

For all $\omega_{i}=\left\langle\left\{i, D_{i}\right\},\left(E_{i}, 0\right),\left(c_{i}, c_{D_{i}}\right)\right\rangle$ there exists $\lambda>0$, where

$\left\{\begin{array}{l}x_{i}^{\mathrm{CEL}}=\min \left\{0, c_{i}-\lambda\right\} \\ x_{D_{i}}^{\mathrm{CEL}}=\min \left\{0, c_{D_{i}}-\lambda\right\} .\end{array}\right.$

\subsubsection{SSR based on Talmud}

For all $\omega_{i}=\left\langle\left\{i, D_{i}\right\},\left(E_{i}, 0\right),\left(c_{i}, c_{D_{i}}\right)\right\rangle$ there exists $\lambda>0$, so that

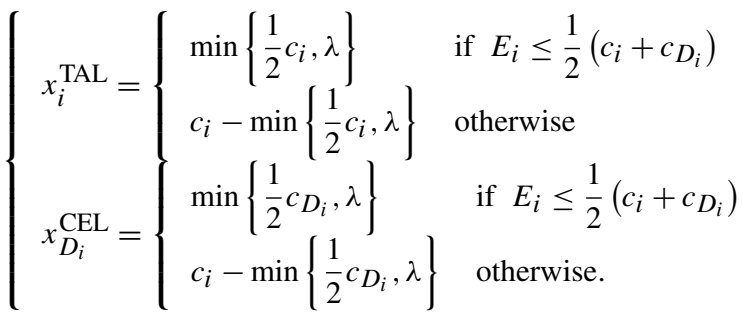

\section{Choosing the best rule}

Due to different definition of "equity", there is no certain documented method to choose the most appropriate allocation rule. While the upstream countries prefer the rules closer to the Absolute Territorial Sovereignty (ATS) doctrine (RieuClarke et al., 2012), the downstream riparian countries prefer the rules with more water allocation to them based on the Absolute Territorial Integrity (ATI) doctrine (Rieu-Clarke et al., 2012). In this paper, a new method is introduced to select the most appropriate allocation rule. Three assumptions should be considered for establishing this method. The first is that all stakeholders have the same power (including military power, economic, social welfares and so on) in negotiation and none of the countries considers its power in consensus building process. The second assumption tells that each country prefers to choose the highest rate of allocation. In other word, each country insists on its claim as other countries. The third assumption is that there is no other solution on the table to allocate the shared water resource.

This method chooses a rule which all stakeholders have the lowest dispersion about their total preferences on that rule. So firstly, the allocations are ranked ascending for each stakeholder, separately. Hence, the priority vectors set, $\boldsymbol{\Omega}$, with elements of $\omega_{i}$ is formed, in which $\omega_{i}$ is a vector with elements of $\vartheta_{j}^{i}$. The vectors $\omega_{i}$ are the preferences vectors. 
Table 2. The allocated water of The Euphrates River among the riparian countries as a percentage of their water demand (\%).

\begin{tabular}{lccccccc|cccc}
\hline Riparian & \multicolumn{7}{c}{ CBR } & \multicolumn{4}{c}{ SSR } \\
\cline { 2 - 11 } & Pro & CEA & CEL & Talmud & Piniles & MO & AP & Pro & CEA & CEL & Talmud \\
\hline Turkey & 65 & 85 & 54 & 54 & 70 & 54 & 58 & 62 & 100 & 32 & 50 \\
Syria & 65 & 94 & 49 & 50 & 72 & 49 & 58 & 66 & 86 & 62 & 50 \\
Iraq & 65 & 42 & 77 & 77 & 60 & 77 & 72 & 66 & 38 & 83 & 79 \\
\hline
\end{tabular}

Table 3. Priority vectors, Priority Index and ranking of eleven CBR and SSR rules.

\begin{tabular}{|c|c|c|c|c|c|c|c|c|c|c|c|}
\hline Country & CBR_Pro & CBR_CEA & CBR_CEL & CBR_Talmud & CBR_Piniles & CBR_MO & CBR_AP & SSR_Pro & SSR_CEA & SSR_CEL & SSR_Talmud \\
\hline Turkey & 2.78 & 5.44 & 0.11 & 2.78 & 4.00 & 0.11 & 0.11 & 0.11 & 13.44 & 25.00 & 9.00 \\
\hline Syria & 0.44 & 11.11 & 11.11 & 0.44 & 4.00 & 11.11 & 0.44 & 1.78 & 7.11 & 0.00 & 4.00 \\
\hline Iraq & 5.44 & 32.11 & 13.44 & 5.44 & 16.00 & 13.44 & 0.11 & 2.78 & 40.11 & 25.00 & 25.00 \\
\hline$\delta_{i}$ & 8.67 & 48.67 & 24.67 & 8.67 & 24.00 & 24.67 & 0.67 & 4.67 & 60.67 & 50.00 & 38.00 \\
\hline Rank & 3 & 9 & 6 & 3 & 5 & 6 & 1 & 2 & 11 & 10 & 8 \\
\hline
\end{tabular}

$i$ and $j$ refers to number of rules and stakeholders, respectively. ( $1 \leq i \leq$ Number of rules, $1 \leq j \leq n$ where $n$ is the number of stakeholders). In the current study, $1 \leq i \leq 11$ and $1 \leq j \leq 3$.

In our study, the priority vectors set, $\boldsymbol{\Omega}$ is $\boldsymbol{\Omega}=$ $\left\{\omega_{1}, \omega_{2}, \ldots, \omega_{11}\right\}$, in which $\omega_{1}=\langle 4,5,8\rangle, \omega_{2}=\langle 2,1,10\rangle$ and $\omega_{11}=\langle 10,9,2\rangle$. By this task each bankruptcy rule corresponds to a priority vector $\omega_{i}$. The best priority vector is the vector with the lowest distance around an intermediate value e.g. average value in this paper, $\overline{\boldsymbol{\omega}}$. The dispersion around the mean of vector $\boldsymbol{i}, \delta_{i}$, is calculated by

$\delta_{i}=\frac{\sum_{j=1}^{n}\left(\vartheta_{j}^{i}-\overline{\boldsymbol{\omega}_{i}}\right)^{2}}{n}=\frac{\sum_{j=1}^{n}\left(\vartheta_{j}^{i}-\frac{\sum_{j=1}^{n} \vartheta_{j}^{i}}{n}\right)^{2}}{n}$.

For example for CBR-MO rule we have:

$\overline{\omega_{6}}=\frac{8+11+4}{3} \approx 7.7$

$\delta_{6}=\delta_{\mathrm{CBP} \_\mathrm{MO}}=\frac{(8-7.7)^{2}+(11-7.7)^{2}+(4-7.7)^{2}}{3} \approx 24.67$.

Table 3 presents $\delta_{i}$ for all rules. Each rule which has the lowest $\delta_{i}$, will be chosen as the most appropriate allocation rule.

\section{Results}

Figure 2 illustrates the allocation of the Euphrates River among three riparian countries by seven CBRs and four SSRs. The allocated water of the Euphrates River among the countries as a percentage of their water demands are presented in Table 2.

The results shown in Fig. 2 indicate that the method of the CBR-CEA allocates the lowest rate of water to Iraq, the most downstream agent, while the SSR-CEL and SSR-Talmud allocate the highest rate of water to Iraq. For the upstream country, Turkey, the most and the least rate of water were allocated by the SSR-CEA and the SSR-CEL, respectively. Based on ATS principle, the SSR-CEA is preferable for upstream countries, while the SSR-CEL is preferable for downstream countries based on ATI principle. Morever the highest and lowest allocations to Syria are assigned by CBR-CEA, CBR-CEL and CBR-MO rules, respectively.

The preferences orders for the three riparian states rules are as follow:

- Turkey: SSR-CEA > CBR-CEA > CBR-Piniles $>$ CBRPro $>$ SSR-Pro $>$ CBR-AP $>$ CBR-CEL $=\mathrm{CBR}-\mathrm{MO}>$ CBR-Talmud $>$ SSR-Talmud $>$ SSR-CEL

- Syria: CBR-CEA > SSR-CEA > CBR-Piniles > SSRPro $>$ CBR-Pro $>$ SSR-CEL $>$ CBR-AP $>$ SSR-Talmud $=$ CBR-Talmud $>$ CBR-CEL $=$ CBR-MO

- Iraq: SSR-CEL > SSR-Talmud > CBR-CEL = CBRMO $>$ CBR-Talmud $>$ CBR-AP $>$ SSR-Pro $>$ CBR-Pro $>$ CPR-Piniles $>$ CBR-CEA $>$ SSR-CEA

According to Table 3 and based on new proposed method CBR_AP and SSR_CEA are proposed as best and worse allocation rules, respectively. Although, allocation to Turkey is the highest rate by SSR-CEA rule and this rule has the highest rank for this country (and second place for Syria) but, as it is illustrated in Table 3, it has the lowest rank for Iraq and only $38 \%$ of Iraq claims is allocated by this method (Table 2). So the more equitable rule is the rule which satisfies the stakeholders in the more appropriate way.

\section{Discussion}

Eleven bankruptcy rules in 2 different views, classical bankruptcy problems and sharing river problem, have been presented in this paper. A new choosing method base on minimal priority index is proposed for selecting the most appropriate rule among these eleven bankruptcy rules. According 


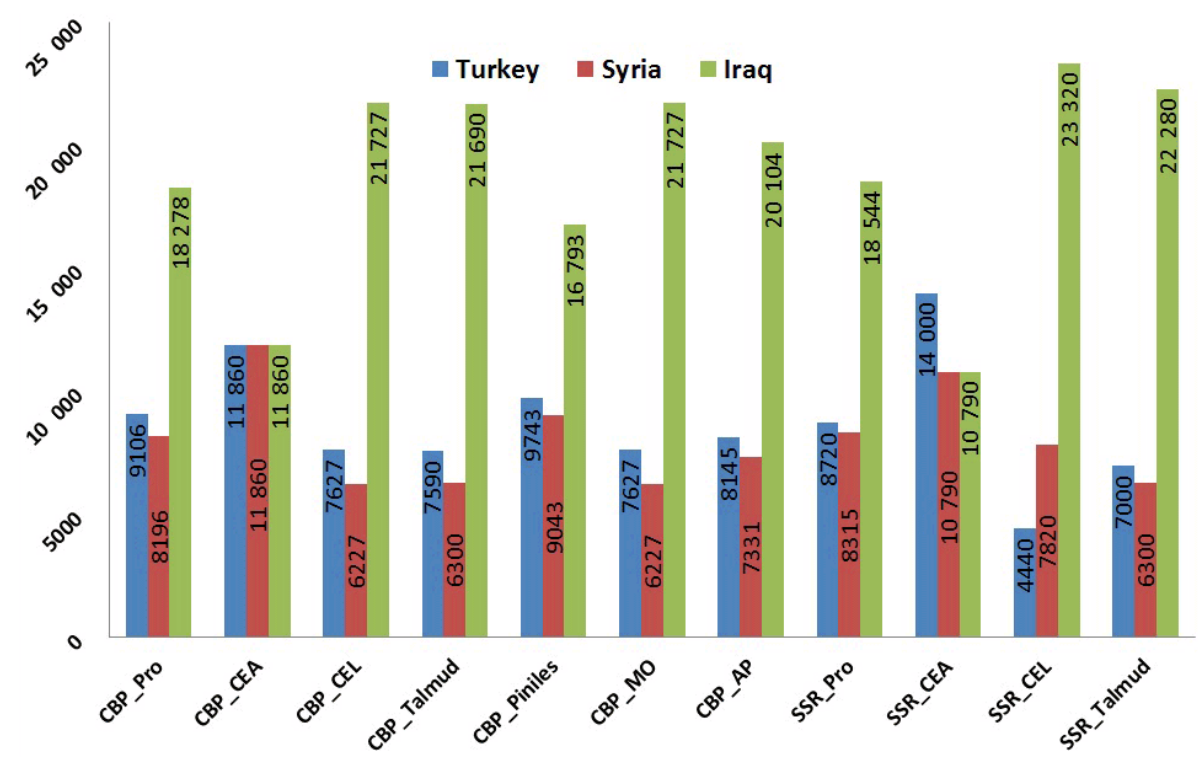

Figure 2. Reallocation of the Euphrates River among three riparian countries by Classic Bankruptcy Rules (CBR) and Sequential Sharing Rules (SSR) methods.

to these indices CBR_AP rule select as the best allocation rule for sharing Euphrates River among the three countries.

No doubt, consensus building depends on several factors including allocation percentage, rate of contribution, the damage to the downstream states due to the development in the upstream countries, compensation to the downstream countries, socio-political conditions, and the benefits of the development for the upstream countries, etc. Some factors that should be considered for equitable and reasonable utilisation of an international watercourse are established at UN Watercourses Convention, Part II (General Principle), article 6 (factor relevant to equitable and reasonable utilization) (Rieu-Clarke et al., 2012). Almost all the factors emphasis that any kind of development along the basin must consider existing use of the watercourse which is referred to "historical uses" (Ansink and Weikard, 2009). However, it should be consider that "Historical Uses" is differs from "Historical rights" (Grover, 2007).

In this research, we established a new method to find the most appropriate allocation rule to satisfy the three countries of Turkey, Syria and Iraq more equitably for water allocation of the Euphrates River. Although the allocation rules can give an appropriate vision to the conflict management of the transboundary water resources, but it should also be noted that reallocation of shared water resources is a complicated problem that it cannot be solved only by some mathematical methods, especially when the power distribution is asymmetric (Susskind, 2006; Madani et al., 2014). Therefore, water diplomacy and triple negotiating among Turkey, Syria and Iraq are suggested to build a consensus and to reach an agreement on this river.

\section{Data availability}

Data are collected from two different articles. (1) doi:10.1007/978-3-662-10866-6_28 by Ibrahim et al. (2004) (2) Restructuring of Water Usage in the Tigris-Euphrates Basin: The Impact of Modern Water Management Policies by Peter Beaumont website (Beaumont et al., 1998): http: //environment.yale.edu/publication-series/796.html.

\section{References}

Alcalde, J., Marco, M., and Silva, J.: The minimal overlap rule revisited, Social Choice and Welfare, 31, 109-128, doi:10.1007/s00355-007-0269-5, 2008.

Alcalde, J., del Carmen Marco-Gil, M., and Silva-Reus, J. A.: The minimal overlap rule: restrictions on mergers for creditors' consensus, Top, 22, 363-383, 2014.

Ansink, E. and Weikard, H.-P.: Contested water rights, European Journal of Political Economy, 25, 247-260, doi:10.1016/j.ejpoleco.2008.09.007, 2009.

Ansink, E. and Weikard, H.-P.: Sequential sharing rules for river sharing problems, Social Choice and Welfare, 38, 187-210, 2012.

Aumann, R. J. and Maschler, M.: Game theoretic analysis of a bankruptcy problem from the Talmud, J. Econ. Theor., 36, 195213, 1985.

Beaumont, P.: Restructuring of water usage in the Tigris-Euphrates basin: the impact of modern water management policies, in: Transformation of Middle Eastern natural environments: Legacies and lessons, edited by: Coppock, J. and Miller, J. A., Publisher: Yale School of forestry \& environmental studies, available at: http://environment.yale.edu/publication-series/796.html, 168-186, 1998. 
Bosmans, K. and Lauwers, L.: Lorenz comparisons of nine rules for the adjudication of conflicting claims, SSRN 958691, 2007.

Chun, Y. and Thomson, W.: Convergence under replication of rules to adjudicate conflicting claims, Games and Economic Behavior, 50, 129-142, 2005.

Curiel, I. J., Maschler, M., and Tijs, S. H.: Bankruptcy games, Zeitschrift für Operations Research, 31, A143-A159, doi:10.1007/BF02109593, 1987.

Dagan, N. and Volij, O.: The bankruptcy problem: a cooperative bargaining approach, Mathematical Social Sciences, 26, 287297, 1993.

De Stefano, L., Duncan, J., Dinar, S., Stahl, K., Strzepek, K. M., and Wolf, A. T.: Climate change and the institutional resilience of international river basins, J. Peace Res., 49, 193-209, 2012.

Dolatyar, M. and Gray, T.: Water Politics in the Middle East: A Context for Conflict Or Co-operation?, Macmillan, 2000.

ESCWA: Inventory of Shared Water Resources in Western Asia ESCWA, 2013

Frenken, K.: Irrigation in the Middle East region in figures AQUASTAT Survey-2008, Water Reports, 2009.

Gleick, P. H.: Water and Conflict: Fresh Water Resources and International Security, International Security, 18, 79-112, doi:10.2307/2539033, 1993.

Grover, V. I.: Water: a source of conflict or cooperation?, Science Publishers, Inc., 2007.

Hendrickx, R., Borm, P., Van Elk, R., and Quant, M.: Minimal overlap rules for bankruptcy, International Mathematical Forum, 61, 3001-3012, 2005.

Homer-Dixon, T. F.: Environmental scarcities and violent conflict: evidence from cases, International Security, 19, 5-40, 1994.

Ibrahim, G., Sonmez, B., Bogardi, J., and Castelein, S.: Water issues among the riparian states of Euphrates and Tigris transboundary rivers, From Conflict to Co-operation in International Water Resources Management: Challenges and Opportunities, International Conference, Delft, the Netherlands, 20-22 November 2002, 344-354, 2004.

Jongerden, J.: Dams and Politics in Turkey: Utilizing Water, Developing Conflict, Middle East Policy, 17, 137-143, doi:10.1111/j.1475-4967.2010.00432.x, 2010.

Kaya, I.: The Euphrates-Tigris basin: An overview and opportunities for cooperation under international law, Arid Lands Newsletter, 44, available at: http://ag.arizona.edu/OALS/ALN/ aln44/kaya.html\#international (last access: August 2015), 1998.
Lorenzo-Freire, S., Casas-Méndez, B., and Hendrickx, R.: The twostage constrained equal awards and losses rules for multi-issue allocation situations, Top, 18, 465-480, 2010.

Madani, K. and Zarezadeh, M.: Bankruptcy methods for resolving water resources conflicts, 2012 World Environmental and Water Resources Congress, 2247-2252, 2012.

Madani, K., Zarezadeh, M., and Morid, S.: A new framework for resolving conflicts over transboundary rivers using bankruptcy methods, Hydrol. Earth Syst. Sci., 18, 3055-3068, doi:10.5194/hess-18-3055-2014, 2014.

Meyers, E. M.: The Oxford encyclopedia of archaeology in the Near East, Oxford University Press, 1997.

Mianabadi, H., Mostert, E., Zarghami, M., and van de Giesen, N.: A new bankruptcy method for conflict resolution in water resources allocation, J. Environ. Manage., 144, 152-159, doi:10.1016/j.jenvman.2014.05.018, 2014.

Mianabadi, H., Mostert, E., Pande, S., and van de Giesen, N.: Weighted Bankruptcy Rules and Transboundary Water Resources Allocation, Water Resour. Manage., 29, 2303-2321, 2015.

O'Neill, B.: A problem of rights arbitration from the Talmud, Mathematical Social Sciences, 2, 345-371, 1982.

Pérez, J. A., Reus, J. A. S., and Gil, M. d. C. M.: A new prospect of additivity in bankruptcy problems, Instituto Valenciano de Investigaciones Económicas, SA (Ivie), 2010.

Prins, G.: Threats without enemies: facing environmental insecurity, Routledge, 2013.

Rieu-Clarke, A., Moynihan, R., and Magsig, B.-O.: UN Watercourses Convention, IHP-HELP Centre for Water Law, Policy and Science (under the auspices of UNESCO), Dundee, 2012.

Susskind, L.: Breaking Robert's rules, Negotiation Journal, 22, 351-355, 2006.

Thomson, W.: Axiomatic and game-theoretic analysis of bankruptcy and taxation problems: a survey, Mathematical Social Sciences, 45, 249-297, 2003.

Thomson, W.: Lorenz rankings of rules for the adjudication of conflicting claims, Economic Theory, 50, 547-569, 2012.

UN Water: UN-Water factsheet on transboundary waters, available at: http://www.un.org/waterforlifedecade/transboundary_waters. shtml, last access: 6 August 2014.

Westing, A. H.: Global resources and international conflict: environmental factors in strategic policy and action, Oxford University Press, 1986. 